\title{
BMJ Open Social group memberships in retirement are associated with reduced risk of premature death: evidence from a longitudinal cohort study
}

\author{
Niklas K Steffens, Tegan Cruwys, Catherine Haslam, Jolanda Jetten, \\ S Alexander Haslam
}

To cite: Steffens NK

Cruwys T, Haslam C, et al. Social group memberships in retirement are associated with reduced risk of premature death: evidence from a longitudinal cohort study. BMJ Open 2016;6:e010164. doi:10.1136/bmjopen-2015010164

- Prepublication history for this paper is available online. To view these files please visit the journal online (http://dx.doi.org/10.1136/ bmjopen-2015-010164)

Received 3 October 2015 Revised 16 December 2015 Accepted 17 December 2015

CrossMark

The University of Queensland, Brisbane, Queensland, Australia

Correspondence to Dr Niklas K Steffens; n.steffens@uq.edu.au

\section{ABSTRACT}

Objectives: Retirement constitutes a major life transition that poses significant challenges to health, with many retirees experiencing a precipitous decline in health status following retirement. We examine the extent to which membership in social groups following retirement determines quality of life and mortality.

Design: The longitudinal impact of the number of social group memberships before and after the transition to retirement was assessed on retirees' quality of life and risk of death 6 years later.

Setting: Nationally representative cohort study of older adults living in England.

Participants: Adults who underwent the transition to retirement $(\mathrm{N}=424)$. A matched control group $(\mathrm{N}=424)$ of participants who had comparable demographic and health characteristics at baseline but did not undergo the transition to retirement were also examined.

Outcome measures: Analyses examined participants' quality of life and mortality during a period of 6 years.

Results: Retirees who had two group memberships prior to retirement had a $2 \%$ risk of death in the first 6 years of retirement if they maintained membership in two groups, a $5 \%$ risk if they lost one group and a $12 \%$ risk if they lost both groups. Furthermore, for every group membership that participants lost in the year following retirement, their experienced quality of life 6 years later was approximately 10\% lower. These relationships are robust when controlling for key sociodemographic variables (age, gender, relationship status and socioeconomic status prior to retirement). A comparison with a matched control group confirmed that these effects were specific to those undergoing the transition to retirement. The effect of social group memberships on mortality was comparable to that of physical exercise.

Conclusions: Theoretical implications for our understanding of the determinants of retiree quality of life and health, and practical implications for the support of people transitioning from a life of work to retirement are discussed.
Strengths and limitations of this study

- This is the first study to examine the protective benefits of social group memberships for quality of life and health in retirement.

- Use of data from a nationally representative sample and longitudinal analysis to follow participants over the transition to retirement.

- Use of reliable measures of (subjective) quality of life and (objective) mortality.

- Comparison of social group memberships relative to physical exercise in terms of their protective benefit for health.

- The main limitation was that the measure of social group memberships was not exhaustive.

\section{INTRODUCTION}

Retiring from work constitutes a major life transition that most people experience at some point in the course of their life, posing significant challenges to health and wellbeing. Indeed, large-scale longitudinal studies indicate that around $25 \%$ of retirees in the $\mathrm{USA}^{1}$ and around $10 \%$ of retirees in Germany $^{2}$ experience a significant drop in health and well-being in the retirement transition. These figures point to the fact that retirement has significant costs for individuals and for society at large.

At the same time, however, such studies reveal significant variation in retirees' experiences and health decline is not universal. Some retirees experience no change in health, and others actually experience improved health. This suggests that, beyond leaving one's job, there are a range of factors that determine whether retirees adjust well or poorly to this transition. In this regard, a growing literature points to the fact that social factors have a profound impact on people's health. For instance, meta-analytic 
evidence $^{3}$ shows that people's social relationships with others is a significant predictor of their longevity and in fact a stronger predictor than other health behaviours such as physical exercise, smoking or alcohol consumption. Similarly, longitudinal evidence indicates that social engagement (or the lack of social isolation) is predictive of several key aspects of health, ${ }^{4-7}$ being associated with reduced depression ${ }^{8}$ and enhanced cognitive health. ${ }^{9}$ Clearly, social connectedness has significant implications for health. So, how and why might social connectedness be relevant for retirees?

In the present paper we argue that part of the variance in health and quality of life of retirees can be explained by the implications that retirement has for people's social group memberships-and their social identities or the sense of self that is derived from membership in one or more social groups. ${ }^{10-12}$ In more formal terms, we define a social group as a group of any form that a person is a member of and that he or she sees as an important part of their identity. For example, these groups can be leisure groups (eg, a book club), family, friendship or community groups (eg, a church group), sporting groups (eg, a tennis club), work groups (eg, a sales team), professional groups (eg, a trade union) or any other groups that a person sees as an important part of who they are. More specifically, we argue that retirement has an important bearing on health and quality of life because it typically involves relinquishing social group memberships (eg, as a member of a particular professional group, a particular organisation, a particular workteam) that have been a key focus for people's selfdefinition for years or decades. At the same time too, it can also provide opportunities to develop new group memberships, and hence for particular forms of socially engaged life. In line with previous work that has pointed to important links between group membership and health, ${ }^{13-15}$ our general argument is that the consequences of retirement for health and quality of life will depend in part on its implications for the constellation of group memberships that define an individual's sense of self.

\section{The process of adjusting to retirement}

Retirement is conceptualised as a developmental process requiring adjustment that spans not only the transition from employment to retirement but also longer-term development post-retirement. ${ }^{16}$ Moreover, one's health and quality of life following the transition to retirement prove to be important indicators of successful retirement. ${ }^{17}$ However, there is significant variability in retirees' health and quality of life, in part because the process of adjustment is shaped by an array of factors including the extent to which an individual participates in (1) financial planning and decision-making in the lead-up to leaving work, ${ }^{18-20}$ (2) bridge or volunteer work $^{21} 22$ (3) leisure activities ${ }^{23} 24$ and (4) physical activity. ${ }^{25} 26$
Moreover, and speaking to the aims of the present research, post-retirement adjustment is also dependent on a person's (5) ongoing social relationships that include family structures and wider social contacts. ${ }^{27} 28$ Such findings are also consistent with the literature showing that social factors have a significant influence on both psychological and general health. ${ }^{3-7} 29-31$

\section{The role of social group memberships in adjustment to retirement}

Speaking to the importance of living a socially fulfilled life, an emerging body of research demonstrates the key role that social group memberships play in protecting health and well-being. People derive a sense of who they are from social groups (ie, their social identity), providing them with a sense of purpose, meaning, agency and belonging. Given their centrality to a person's sense of self, it is not surprising that when they are compromised this constitutes a major threat to psychological and social functioning. ${ }^{13} 1432$ In line with this point, there is evidence that the number of groups that a person is a member of is a unique predictor of self-esteem, ${ }^{33}$ resilience $^{34}$ and mental health. ${ }^{35-37}$

A growing body of research also supports claims that group-based interactions have a distinctive role to play in health and well-being over and above social interaction and social contact per se. ${ }^{15} 38{ }^{39}$ Indeed, belonging to a greater number of social groups has been shown to be particularly protective of health when people undergo stressful life transitions such as becoming a university student, ${ }^{40}$ recovering from a stroke ${ }^{41}$ or coming to terms with a brain injury. ${ }^{42}$

Building on this body of research, we hypothesise that social group memberships will have an important role to play in adjustment to retirement. This is because transitioning to retirement is characterised by social losses associated with giving up work-related group memberships and associated identities. ${ }^{43}$ Speaking to this possibility, the present research is the first to examine the contribution that social group memberships-both old and new-make to post-retirement adjustment. In line with previous research, our core prediction is that once people have stopped work and are in the process of adapting to their new life circumstances, access to more group memberships will be a significant and unique predictor of successful adjustment. In this regard, the Social Identity Model of Identity Change (SIMIC) ${ }^{44}$ suggests that group memberships can offer protection against the stress-producing health consequences of life change. Moreover, it asserts that they do this in two ways; through (1) a continuity pathway involving the maintenance of old group memberships following the change and (2) a gain pathway involving the acquisition of new group memberships following the change.

While continuity of group memberships following retirement and gaining new group memberships following retirement might be equally effective in protecting retirees' health and quality of life, the maintenance 
pathway is likely to be less common among retirees. Whereas some may experience continuity of workrelated identities through gradual transition to retirement, voluntary work or other means, this is not the case for everyone. Accordingly, for those who fully retire, the gain pathway of joining new groups following the transition might be particularly important because it can counter the experience of loss where work-related identities had been valued.

\section{Overview of present research}

In the present research, we examine the relationship between the number of social group memberships and adjustment to retirement through analysis of data from the English Longitudinal Study of Ageing (ELSA). This allows us to test the contribution that social group memberships make to retirement adjustment as indexed by (subjective) quality of life and (objective) mortality in a large longitudinal sample. Based on the above reasoning, we expect that continuity of pre-retirement social group memberships will be less important than gain of new group memberships in protecting the quality of life and health of people who are transitioning to retirement. We test this prediction through comparison with a comparably matched control group (who are either still working or have already transitioned to retirement) for whom continuity would be likely to be achieved and important for quality of life and health. Moreover, we also compare the strength of the effect of social group memberships on health to that of physical exercise. Stated more formally, we propose the following hypotheses:

H1. The number of social groups that retirees report being members of following retirement will predict their (a) quality of life, and (b) mortality. Social group memberships will predict health even after controlling for key sociodemographic variables (age, gender, relationship status and socioeconomic status).

$H 2 a$. Among retirees, the number of social groups postretirement (at time 2; after the transition) will be more important in predicting quality of life and mortality than the number of social groups pre-retirement (at time 1).

$H 2 b$. Among a matched control group, who have not undergone an identity transition between Time 1 and Time 2 (because they are still working or have retired prior to the time period of the study), the initial number of groups (at Time 1 rather than at Time 2) will be a predictor of quality of life and mortality.

\section{METHOD}

\section{Participants and design}

Retiree sample

Participants were 424 respondents of the ELSA who retired between wave 1 (W1) and wave 2 (W2) and had sufficient data available on the variables of interest. The ELSA sample was drawn from households previously responding to the Health Survey for England, with all respondents born before March 1952. The English
Longitudinal Study of Ageing started in 2002-2003, constituting W1, with respondents invited to participate every 2 years. The most recent release of mortality data is wave 5 (W5), collected in 2010-2011. While wave 6 (W6) was available at the time of the present analysis, mortality data for W6 was not available and so W5 was the most complete wave available for our purposes. All participants were aged 50 years or more and were residing in England when surveyed.

\section{Matched control group}

To provide evidence that findings uniquely relate to the transition to retirement (rather than being a more general phenomenon unrelated to this transition) we identified a matched control group of 424 respondents who were highly similar to retirees on demographic variables, but who were not currently transitioning to retirement. Therefore, in the matched control group any change in group membership between waves 1 and 2 did not relate to transition to retirement. Using the 'fuzzy' SPSS extension, for each participant in the retiree sample we identified a matched control from the ELSA data set. Specifically, to account for sample variation while ensuring that this procedure generated a comparable sample (of identical size), we specified that cases in the matched control group were allowed to vary on the following continuous variables: age by no more than 2 years, and subjective physical health, number of groups and quality of life by no more than one point on the scale, while matching cases as far as possible on the categorical variables gender, ethnicity, relationship status and socioeconomic status. Subjective physical health, number of groups and quality of life (all at W1) were also matched, while allowing scores to differ by 1 on these variables. The demographics of retirees and matched controls are presented in table 1 and these indicate that the two groups did not differ statistically at W1 on any variables other than work status. The available sample size for mortality is larger than that for quality of life because for some participants who did not take part in a follow-up wave, the ELSA draws on other sources to gather mortality data. We refrained from using survey weights to deal with attrition. It is noteworthy that attrition was comparable in the target and matched control group.

\section{Measures}

\section{Social group memberships}

Following the logic of previous research, ${ }^{36} 38$ respondents' number of group memberships was determined from their response to the question: "Are you a member of any of the following organizations, clubs or societies?" Respondents could tick any or all of eight response options (eg, 'social clubs'; 'church or other religious groups'). Respondents could also tick a final box: "No I am not a member of any organizations, clubs or societies." Responses were summed to create a continuous scale ranging from 0 to 8 . 
Table 1 Descriptive statistics for retirees and matched controls

\begin{tabular}{lll}
\hline & $\begin{array}{l}\text { Retirees (N=424) } \\
\text { Results at wave 1 (2002) unless } \\
\text { otherwise specified }\end{array}$ & $\begin{array}{l}\text { Matched controls (N=424) } \\
\text { Results at wave 1 (2002) unless } \\
\text { otherwise specified }\end{array}$ \\
\hline Work status & $100 \%$ employed at W1 & $58.3 \%$ employed at W1+W2 \\
& $100 \%$ retired at W2 & $41.7 \%$ retired at W1+W2 \\
Age (top-coded at 90$)$ & $60.52(4.85)$ & $59.88(5.22)$ \\
Sex & $46.5 \%$ female & $47.2 \%$ female \\
Relationship status & $71.2 \%$ married, 6.4\% cohabiting, 22.4\% & $75.9 \%$ married, 3.1\% cohabiting, 21\% \\
& neither (single, divorced or widowed) & neither (single, divorced or widowed) \\
Subjective physical health & $3.16(0.90)$ & $3.25(0.98)$ \\
Quality of life & $1.51(0.66)$ & $1.40(0.65)$ \\
Socioeconomic status (1-10 decile) & $6.96(2.75)$ & $6.72(2.84)$ \\
Number of groups (range 0-8) & $1.56(1.54)$ & $1.55(1.39)$ \\
Deceased at W5 & W2: $1.39(1.40)$ & $23(5.4 \%)$ \\
\hline
\end{tabular}

\section{Dependent variables}

Two reliable measures were used: quality of life (subjective) and mortality (objective). In both cases, we were interested in predicting long-term adjustment outcomes and so examined respondents' life quality and mortality in the most recent wave of available data (W5). For each analysis, we aimed to predict retirees' quality of life and mortality 6 years post-retirement from their group memberships in the wave following their retirement (W2) while controlling for both indices immediately prior to retirement $(\mathrm{W} 1)$.

\section{Quality of life}

Participants responded to the 5-item Satisfaction With Life Scale assessing quality of life (eg, "In most ways, my life is more or less ideal"). ${ }^{45-48}$ At W1, only the single item assessing quality of life was available in the data set ("I feel satisfied with the way my life has turned out") and we controlled for this W1 measure in the quality of life analyses. Items were scored on a 7-point scale that was recoded as a summary score from 1 'strongly disagree' to 7 'strongly agree'.

\section{Mortality}

For those participants who could not be contacted to complete the survey at W3, W4 or W5, ELSA draws on mortality records from the Office of National Statistics to determine whether participants were deceased. For the purposes of our analysis, this variable was coded as 0 'not deceased' or 1 'deceased'.

\section{Covariates}

Five covariates were included in the analyses. These were age (top-coded at 90 years), gender, relationship status (married, de-facto or neither), and socioeconomic status (based on decile of annual reported income). In addition, we controlled for dependent variables preretirement (W1). For the analysis of quality of life, W1 data for this variable was included as a covariate. For the analysis of mortality, W1 subjective physical health ("How often does your health stop you from doing what you want to do?" rated on a 5-point scale ranging from 'never' to 'often') was included as a covariate given that it is (obviously) not possible to control for prior levels of mortality. By controlling for initial quality of life and health, we reduced the likelihood that the results could be accounted for by pre-existing differences in outcome variables between those with many group memberships and those without.

\section{Procedure and statistical analysis}

ELSA data collection consists of two separate modules: an interview, conducted in-person using computerassisted interviewing and a questionnaire which participants complete independently. The more sensitive and/ or subjective questions, including those measuring group memberships and quality of life, were part of the self-completed questionnaire.

To analyse the results, we used hierarchical regression in which control variables were entered in step 1 , while W1 group memberships were added in step 2, and W2 group memberships in step 3. We used linear regression to assess the continuous variable quality of life and binary logistic regression to assess the categorical variable mortality.

\section{RESULTS}

\section{Main analyses}

Quality of life

Hierarchical regression was used to model quality of life at W5, with results presented in table 2. Initial quality of life prior to retirement was the only significant covariate, such that respondents who experienced high quality of life at W1 were also more likely to have higher quality of life 8 years later. Consistent with H1a, the number of groups that respondents reported being members of following retirement (at W2) was also a significant predictor. Supporting H2a, group memberships only had 
Table 2 Group memberships increase quality of life (W5)

\begin{tabular}{|c|c|c|c|c|c|c|c|c|}
\hline & \multicolumn{4}{|c|}{ Retirees ( $\mathrm{N}=296)$} & \multicolumn{4}{|c|}{ Matched controls $(\mathrm{N}=302)$} \\
\hline & $\mathrm{R}^{2}$ change & b & SE & Semipartial $r$ & $\mathbf{R}^{2}$ change & b & SE & Semipartial $r$ \\
\hline Step $1 \mathrm{~W} 1$ variables & $0.10^{\star * \star}$ & & & & $0.12^{\star \star \star}$ & & & \\
\hline Age & & -0.01 & 0.01 & -0.05 & & 0.00 & 0.01 & -0.01 \\
\hline Sex & & 0.12 & 0.13 & 0.05 & & -0.10 & 0.12 & -0.05 \\
\hline Quality of life & & 0.51 & 0.10 & $0.29^{\star \star \star}$ & & 0.64 & 0.10 & $0.34^{* * *}$ \\
\hline Relationship status & & 0.05 & 0.08 & 0.04 & & -0.04 & 0.08 & -0.03 \\
\hline Socioeconomic status & & 0.00 & 0.02 & 0.01 & & 0.01 & 0.02 & 0.03 \\
\hline Step 2 & 0.00 & & & & $0.02^{\star \star}$ & & & \\
\hline W1 Group memberships & & -0.03 & 0.04 & -0.04 & & 0.11 & 0.04 & $0.14^{* *}$ \\
\hline Step 3 & $0.01^{*}$ & & & & 0.01 & & & \\
\hline W2 Group memberships & & 0.12 & 0.06 & $0.12^{*}$ & & -0.09 & 0.05 & -0.09 \\
\hline
\end{tabular}

Entries are for variables at the stage at which they are entered into the model.

${ }^{*} p<0.05,{ }^{* *} p<0.01,{ }^{* *} p<0.001$.

additional predictive power when this was a post-transition measure (at W2 but not at W1; ie, for transitioning retirees only). Indeed, for every group membership that participants lost following retirement, their quality of life 6 years later was approximately $10 \%$ lower.

In contrast, among the matched control group, change in group memberships in this period did not significantly affect quality of life. Instead, H2b was confirmed for quality of life, as among respondents who did not undergo the transition to retirement only the number of their initial group memberships (ie, at W1 but not at W2) had additional predictive power. For every group membership a participant had at W1, their quality of life was approximately $9 \%$ higher 8 years later.

\section{Mortality}

Twenty-eight $(6.6 \%)$ of the retiree sample died in the first 6 years of their retirement. We used stepwise binary logistic regression to model the likelihood of death based on our demographic, health and social variables of interest. As can be seen in table 3, the strongest predictor of death was age, such that someone aged 55 at retirement had a $1 \%$ chance of dying in the following
6 years, while someone aged 65 at retirement had an $8 \%$ chance of dying in the following 6 years. It is noteworthy too, that while subjective physical health was a significant predictor of mortality on its own (when one does not control for any other variable), $\chi^{2}(1)=4.74, p=0.030$, Exp (b) $=0.779$, as presented in table 3 , it was not a significant predictor when the variables of the present analyses are also included as predictors.

However, consistent with $\mathrm{H} 1 \mathrm{~b}$, the only other significant predictor of death in the model was number of group memberships following retirement. Supporting H2a, group memberships only had additional predictive power when this was a post-transition measure (at W2; ie, for transitioning retirees only). For purposes of illustration, if participants had two group memberships prior to retirement, their risk of death over the first 6 years of retirement was $2 \%$ if they maintained membership in two groups, but was 5\% if they lost one group, and $12 \%$ if they lost both groups. These results are presented in figure 1 .

In contrast, among the matched control group who did not retire between $\mathrm{W} 1$ and W2, change in group memberships in this period was not a significant predictor of risk of death. Instead, supporting H2b, their

Table 3 Group memberships protect against mortality (W3-W5)

\begin{tabular}{|c|c|c|c|c|c|c|c|c|}
\hline & \multicolumn{4}{|c|}{ Retirees $(\mathrm{N}=410)$} & \multicolumn{4}{|c|}{ Matched controls $(\mathrm{N}=424)$} \\
\hline & $\mathrm{R}^{2}$ change & b & SE & OR & $\mathbf{R}^{2}$ change & b & SE & OR \\
\hline Step $1 \mathrm{~W} 1$ variables & $0.15^{\star \star \star}$ & & & & $0.10^{*}$ & & & \\
\hline Age & & 0.15 & 0.04 & $1.16^{\star \star \star}$ & & 0.12 & 0.04 & $1.13^{\star \star}$ \\
\hline Sex & & -0.78 & 0.47 & 0.46 & & 0.47 & 0.46 & 1.59 \\
\hline Subjective physical health & & 0.02 & 0.14 & 1.02 & & -0.32 & 0.18 & 0.72 \\
\hline Relationship status & & -0.08 & 0.26 & 0.92 & & 0.11 & 0.25 & 1.11 \\
\hline Socioeconomic status & & 0.06 & 0.08 & 1.07 & & -0.07 & 0.08 & 0.94 \\
\hline Step 2 & 0.01 & & & & $0.07^{\star \star}$ & & & \\
\hline W1 Group memberships & & -0.24 & 0.16 & 0.79 & & -0.66 & 0.24 & $0.52^{\star \star}$ \\
\hline Step 3 & $0.08^{\star \star \star}$ & & & & 0.02 & & & \\
\hline W2 Group memberships & & -0.85 & 0.25 & $0.43^{* * *}$ & & 0.26 & 0.14 & 1.29 \\
\hline
\end{tabular}

Entries are for variables at the stage at which they are entered into the model.

${ }^{*} p<0.05,{ }^{* *} p<0.01,{ }^{* * *} p<0.001$. 


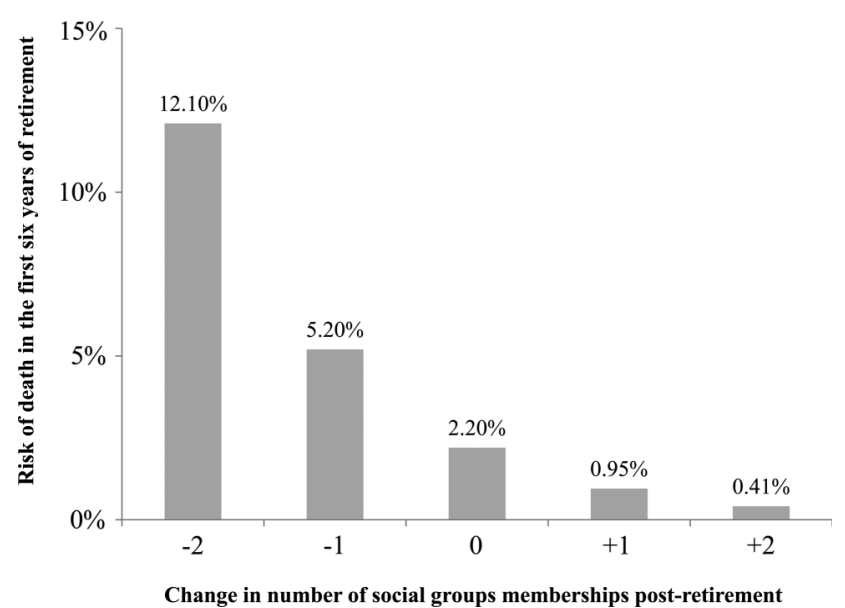

Figure 1 Change in number of social group memberships from pre-retirement to post-retirement predicts likelihood of death in the first 6 years of retirement $(\mathrm{N}=410)$. Results are based on binary logistic regression that controls for age, sex, subjective physical health, relationship status, socioeconomic status. Probability estimates are presented for a person who had two social group memberships prior to retirement.

number of initial group memberships (W1) was the only predictor. A respondent with no groups at W1 had approximately $10 \%$ chance of dying over the following 8 years, while for a respondent with two groups at W1 the risk was only $2 \%$.

\section{Additional analyses}

Socioeconomic status can also be assessed by variables other than income. To examine whether other indicators of socioeconomic status affected the present relationships, we ran additional sensitivity analyses in which we controlled for wealth and education. Results of a regression analysis predicting quality of life indicated that retirees' wealth decile $(b=-0.058, p=0.033)$ and education level $(b=-0.057, p=0.085)$ contributed to the prediction of quality of life at W5. To further explore this, we ran analyses including wealth decile and education as additional covariates in our original model of retiree quality of life. When these two variables were added as additional covariates, neither emerged as a significant predictor of quality of life over and above the other covariates (education level was marginally significant; $b=$ $-0.057, \mathrm{p}=0.079$ ) and the results were substantively identical.

Similarly, results of a logistic regression predicting retirees' mortality confirmed that W1 wealth decile $(b=0.12, p=0.088$, Wald's $\mathrm{F}=2.92)$ and $\mathrm{W} 1$ education level $(b=0.22, p=0.025$, Wald's $F=5.03)$ contributed to the prediction of mortality. When added as additional predictors, neither was a significant predictor of mortality over and above other covariates (education level was marginally significant; $b=0.19, p=0.066$ ), and the results were substantively identical.

Another variable that is often seen to be critical for retirees' objective health is physical activity. ${ }^{49-53}$ For comparison purposes, we ran a regression that assessed whether change in physical activity across the same time period (controlling for initial physical activity) affected mortality and compared the magnitude of this effect to the effect of group membership change. Change in physical activity significantly predicted risk of mortality for retirees (Nagelkereke $\mathrm{R}^{2}$ change $=0.032, \mathrm{p}=0.029$; OR 1.62) and marginally predicted mortality for matched controls (Nagelkereke $\mathrm{R}^{2}$ change $=0.025, \mathrm{p}=0.066$; OR $1.54)$. In physical health terms, if a person exercised vigorously once per week before retiring and maintained this frequency post-retirement, they had a $3 \%$ chance of dying in the next 6 years, a $6 \%$ chance if they decreased this frequency to less than weekly and an $11 \%$ chance if they stopped exercising vigorously altogether. Among matched controls across the same time period, a person who maintained weekly vigorous exercise had a $3 \%$ chance of dying in the next 6 years, a $5 \%$ chance if they reduced this frequency to less than weekly and an $8 \%$ chance if they stopped exercising vigorously altogether. Accordingly, we can see that the effects of physical activity on health were comparable to those associated with maintaining old group memberships and developing new ones.

\section{DISCUSSION}

The present research aimed to examine the extent to which social group memberships contribute to retirement adjustment. Supporting H1, findings indicated that retirees who had more social group memberships following their transition to retirement had better (1) quality of life and (2) objective health (in terms of reduced likelihood of dying). Supporting H2a, results showed that greater quality of life and reduced mortality were predicted, in particular, by group memberships post-retirement (and not pre-retirement). Consistent with $\mathrm{H} 2 \mathrm{~b}$, the opposite was the case for a matched nonretirement sample in which initial group memberships had particular predictive power. This pattern suggests that group memberships have a distinct role to play in the process of adapting to new circumstances following retirement; effects that are comparable in size to those of physical activity.

These findings have a number of important implications for retirement research and practice. Adjustment to retirement has been conceptualised as a developmental process, ${ }^{17}$ leading to calls for longitudinal studies that track people's transition to retirement as well as their longer term development. Indeed, gaining a better understanding of the ways in which this transition unfolds is important given that people differ markedly from each other in their experience of adjustment following retirement. ${ }^{1}{ }^{2}$ In this regard, the novel insight provided by the present research is that the number of group memberships post-retirement is an important source of variation in retirees' life trajectories. Expanding on previous research on the health 
protective effects of social group memberships, ${ }^{35}{ }^{42}$ the present research suggests that retirement can also be usefully conceptualised as an identity change process $^{13} 4054$ and that the loss of a workplace group membership associated with retirement is less likely to compromise health and quality of life to the extent that retirees are able to maintain other group memberships and join new groups once retired.

Two further features of our findings are noteworthy. First, even though subjective and objective indicators of health and well-being can differ at times (and some behaviours may impact only one or the other),${ }^{55}$ social group memberships appear to have a generalised relationship to experienced life quality and health as evidenced by the fact that they contribute to two quite distinct indicators: quality of life $^{56-58}$ and mortality. Second, it is apparent that the number of social group memberships predicted subsequent quality of life and health in retirees even after controlling for initial quality of life and health as well as sociodemographic covariates known to be potential reliable predictors: age, gender, relationship status and socioeconomic status. ${ }^{59}$

Speaking further to the importance of social group memberships as a predictor of both quality of life and mortality, it is notable that the present effects were comparable in size to those associated with physical activity - a behaviour widely recognised as enhancing objective health in retirees and older adults more generally. ${ }^{49}$ Interesting too is the fact that these findings are consistent with the growing body of work demonstrating the need for interventions that seek to promote people's adjustment to life transitions by focusing on the management of their group memberships. ${ }^{256061}$ The particular contribution of the present paper in this regard is to further enhance theory in showing that the group membership gain pathway to health and quality of life may be more important than the group membership maintenance pathway particularly where there are challenges to group membership continuity-as there are in the transition to retirement.

These findings also have unique practical implications for retirement planning. First, they suggest that as much as practitioners may help retirees adjust by providing support with financial planning, they may also help by providing social planning. In this regard, practical interventions should focus on helping retirees to maintain their sense of purpose and belonging by assisting them to connect to groups and communities that are meaningful to who they are. More specifically, interventions that focus on facilitating the development of new group memberships post-retirement may be particularly important in sustaining retirees' long-term adjustment.

\section{Limitations and future research}

Although our results provide support for the hypothesised relationships tested, we need to recognise a number of limitations. First, our analysis relied on the best indicator of the number of group memberships available in the ELSA data set. This required people to indicate their group memberships from a large, but preselected list of groups. Clearly it would have been more desirable to have an index of the number of social group memberships that allowed people to self-generate the groups they belonged to in addition to an indicator of the importance of each group for their sense of self (eg, as in a self-generated group listing task). ${ }^{41} \mathrm{Had}$ it been possible to include such a measure-and for our analysis as a whole to thus be more nuanced-we think it is highly likely that our analysis would have been able to capture additional variance. Similarly, the available data did not include a reliable measure of group membership continuity, which meant that we had to rely on groups reported at $\mathrm{W} 1$ as a proxy for groups gained, lost and maintained at W2 (following retirement). To advance our understanding of issues of group membership continuity in identity transitions, future research should include specific objective measures of identity continuity as well as subjective measures tapping into people's experiences of such continuity.

Second, while our results provide clear support for the hypothesised association between our variables, they do not provide evidence that maintaining and developing group memberships has a causal impact on life quality and mortality (eg, due to additional variables that we did not account for). Beyond this, while group memberships may have a causal impact on quality of life and health, these relationships are also likely to be bidirectional such that health may also affect people's ability to engage with their group memberships. Nevertheless, controlling for initial levels of the independent and dependent variables allowed us to isolate the impact of a change in the predictor (group memberships) on change in the dependent variables quality of life and mortality (in the case of the latter we controlled for subjective physical health). Certainly, not least on the basis of a wealth of other evidence, ${ }^{14} 1533344041$ we believe that the potential causal impact of social group memberships on quality of life and health is an important issue that has significant practical implications. It remains, however, that in the case of retirement, this causal relationship can only be conclusively demonstrated in future work using experimental or intervention methods-in particular, by examining the extent to which an intervention that facilitates retirees' membership in social groups can be beneficial for subsequent adjustment and health. Research of this form is currently underway, to address precisely this issue.

Furthermore, there was some attrition in our sample. It is worth noting that an analysis of attrition in the ELSA $^{62}$ indicates that there are few individual-level characteristics that predict subsequent attrition and that attrition is not due to prior disease prevalence, providing some assurance that the present relationships relating to quality of life and health are not due to biased attrition. We would also like to note that we specified characteristics of the matched control group to ensure 
that this group was of identical size and had characteristics that were as similar as possible to those of the retiree group. The fact that the rate of attrition was comparable between these groups (we retained N=296 retirees and $\mathrm{N}=302$ matched controls for the analysis of quality of life, and $\mathrm{N}=410$ retirees and $\mathrm{N}=424$ matched controls for the analysis of mortality) while the focal relationships differ in these groups provides some additional assurance that attrition is unlikely to account for the present relationship.

Finally, even though the present sample allowed us to track a very large number of retirees, in future research it would clearly be valuable to examine the hypothesised relationships in other contexts and samples. For instance, there would be value in examining the extent to which the relationship between group memberships and quality of life and health holds in semiretired individuals (including those who engage in bridge or volunteer work). ${ }^{63}$ Relatedly, it is conceivable that group memberships also have a bearing on retirement planning and the general decision-making processes that retirees engage in such that those with a greater number of non-work related group memberships may, for instance, be less willing to prolong their working life. Moreover, it is also possible that the perceived compatibility between different social group memberships has an additional role to play in affecting adjustment (such that the health-fostering impact of group memberships is more pronounced to the extent that memberships are compatible with each other). Such possibilities raise important questions and avenues for future research.

\section{CONCLUSION}

The present research sought to extend previous research through a longitudinal examination of the extent to which the health and quality of life of newly-retired individuals is impacted by social group memberships. Findings provide consistent support for hypothesised relationships in showing that, even after controlling for sociodemographic variables, the number of groups that retirees are members of is a predictor of both their subsequent quality of life and their likelihood of dying; being as good a predictor as physical activity. In showing that it is group memberships following (rather than prior to) retirement that determine long-term life and health quality, findings also indicate that group memberships play a unique role in the transition to retirement by affecting people's health and quality of life once they cease formal employment. Importantly, these findings not only identify a new locus for retirement research but also suggest a new avenue for practical intervention.

Contributors NKS, TC, CH, JJ and SAH participated in the design of the research. TC performed the statistical analyses. NKS drafted the manuscript. All authors edited the manuscript. All authors read and approved the final manuscript.

Funding This research was supported by two grants from the Australian Research Council awarded to JJ (FT110100238) and SAH (FL110100199).
The funding body did not play any role in the research design; in the collection, analysis, and interpretation of data; in the writing of the manuscript; or in the decision to submit the manuscript for publication.

Competing interests None declared.

Ethics approval Ethical approval for all ELSA waves was granted from the UK's National Research and Ethics Committee. For further information see http://www.hra.nhs.uk

Provenance and peer review Not commissioned; externally peer reviewed.

Data sharing statement No additional data are available.

Open Access This is an Open Access article distributed in accordance with the Creative Commons Attribution Non Commercial (CC BY-NC 4.0) license, which permits others to distribute, remix, adapt, build upon this work noncommercially, and license their derivative works on different terms, provided the original work is properly cited and the use is non-commercial. See: http:// creativecommons.org/licenses/by-nc/4.0/

\section{REFERENCES}

1. Wang M. Profiling retirees in the retirement transition and adjustment process: examining the longitudinal change patterns of retirees' psychological well-being. J Appl Psychol 2007;92:455-74.

2. Pinquart $M$, Schindler I. Changes of life satisfaction in the transition to retirement: a latent-class approach. Psychol Aging 2007;22:442-55.

3. Holt-Lunstad J, Smith TB, Layton JB. Social relationships and mortality risk: a meta-analytic review. PLoS Med 2010;7:e1000316.

4. Cacioppo JT, Hawkley LC, Crawford LE, et al. Loneliness and health: potential mechanisms. Psychometric Med 2002;64:407-17.

5. Cohen S. Social relationships and health. Am Psychol 2004;59:676-84.

6. Putnam R. Bowling alone: the collapse and revival of American community. New York: Simon \& Schuster, 2000.

7. Uchino BN. Understanding the links between social support and physical health: a lifespan perspective with emphasis on the separability of perceived and received support. Perspect Psychol Sc 2009;4:236-55.

8. Cacioppo JT, Hughes ME, Waite LJ, et al. Loneliness as a specific risk factor for depressive symptoms: cross-sectional and longitudinal analyses. Psychol Aging 2006;21:140-51.

9. Ertel KA, Glymour MM, Berkman LF. Effects of social integration on preserving memory function in a nationally representative US elderly population. Am J Public Health 2008;98:1215-20.

10. Ellemers N. The group self. Science 2012;336:848-52.

11. Haslam SA. Psychology in organizations: the social identity approach. London \& Thousand Oaks, CA, US: Sage, 2004

12. Tajfel $\mathrm{H}$, Turner JC. An integrative theory of intergroup conflict. In: Austin WG, Worchel S, eds. The social psychology of intergroup relations. Monterey, CA: Brooks/Cole, 1979:33-47.

13. Haslam SA, Jetten J, Postmes $\mathrm{T}$, et al. Social identity, health and well-being: an emerging agenda for applied psychology. App Psychol 2009;58:1-23.

14. Jetten J, Haslam C, Haslam SA, eds. The social cure: identity, health and well-being. New York: Psychology Press, 2012.

15. Sani F, Madhok V, Norbury M, et al. Greater number of group identifications is associated with healthier behaviour: evidence from a Scottish community sample. Br J Health Psychol 2015;20:466-81.

16. Wang $\mathrm{M}$, Henkens $\mathrm{K}$, van Solinge $\mathrm{H}$. A review of theoretical and empirical advancements. Am Psychol 2011;66:204-13.

17. Wang M, Shi J. Psychological research on retirement. Ann Rev Psychol 2014;65:209-33.

18. Adams GA, Rau BL. Putting off tomorrow to do what you want today planning for retirement. Am Psychol 2011;66:180-92.

19. Feldman DC, Beehr TA. A three-phase model of retirement decision making. Am Psychol 2011;66:193-203.

20. Topa G, Moriano JA, Depolo M, et al. Antecedents and consequences of retirement planning and decision-making: a meta-analysis and model. J Vocat Behav 2009;75:38-55.

21. Deller J, Liedtke PM, Maxin LM. Old-age security and silver workers: an empirical survey identifies challenges for companies, insurers and society. Geneva Papers Risk Insurance-Issues Practice 2009;34:137-57.

22. Kim S, Feldman DC. Working in retirement: the antecedents of bridge employment and its consequences for quality of life in retirement. Acad Management J 2000;43:1195-210. 
23. Dorfman LT, Kolarik DC. Leisure and the retired professor: occupation matters. Educ Geront 2005;31:343-61.

24. Nimrod G. Retirees' leisure: activities, benefits, and their contribution to life satisfaction. Leisure Stud 2007;26:65-80.

25. Lord SR, Castell S, Corcoran J, et al. The effect of group exercise on physical functioning and falls in frail older people living in retirement villages: a randomized, controlled trial. J Am Geriatrics Society. 2003;51:1685-92.

26. Nimrod G, Janke MC, Kleiber DA. Expanding, reducing, concentrating and diffusing: activity patterns of recent retirees in the United States. Leisure Sciences 2008;31:37-52.

27. Reitzes DC, Mutran EJ. The transition to retirement: stages and factors that influence retirement adjustment. Int $J$ Aging Hum Dev 2004;59:63-84.

28. Szinovacz ME, Davey A. Honeymoons and joint lunches: effects of retirement and spouse's employment on depressive symptoms. $J$ Geront Series B: Psychol Sci Soc Sci 2004;59:233-45.

29. Berkman LF. The role of social relations in health promotion. Psychosom Med 1995;57:245-54.

30. Boden-Albala B, Litwak E, Elkind MS, et al. Social isolation and outcomes post stroke. Neurology 2005;64:1888-92.

31. Christakis NA, Fowler $\mathrm{JH}$. The collective dynamics of smoking in a large social network. N Engl J Med 2008;358:2249-58.

32. Cruwys T, Haslam SA, Dingle GA, et al. Depression and social identity: an integrative review. Pers Soc Psychol Rev 2014;18:215-38.

33. Jetten J, Branscombe NR, Haslam SA, et al. Having a lot of a good thing: multiple important group memberships as a source of self-esteem. PLOS ONE 2014;10:e0124609.

34. Jones JM, Jetten J. Recovering from strain and enduring pain multiple group memberships promote resilience in the face of physical challenges. Soc Psychol Pers Sci 2011;2:239-44.

35. Brook AT, Garcia J, Fleming M. The effects of multiple identities on psychological well-being. Pers Soc Psychol Bull 2008;34:1588-600.

36. Cruwys T, Dingle GA, Haslam C, et al. Social group memberships protect against future depression, alleviate depression symptoms and prevent depression relapse. Soc Sci Med 2013;98:179-86.

37. Thoits PA. On merging identity theory and stress research. Soc Psychol Quart 1991;52:22-34.

38. Haslam C, Cruwys T, Haslam SA. "The we's have it": evidence for the distinctive benefits of group engagement in enhancing cognitive health in aging. Soc Sci Med 2014;120:57-66.

39. Sani F, Herrera M, Wakefield JR, et al. Comparing social contact and group identification as predictors of mental health. $\mathrm{Br} J \mathrm{Soc}$ Psychol 2012;51:781-90.

40. Iyer A, Jetten J, Tsivrikos D, et al. The more (and the more compatible) the merrier: multiple group memberships and identity compatibility as predictors of adjustment after life transitions. Br J Soc Psychol 2009:48:707-33.

41. Haslam C, Holme A, Haslam SA, et al. Maintaining group memberships: social identity predicts well-being after stroke. Neuropsychol Rehab 2008;18:671-91.

42. Jones JM, Haslam SA, Jetten J, et al. That which doesn't kill us can make us stronger (and more satisfied with life): the contribution of personal and social changes to well-being after acquired brain injury. Psychol Health 2011;26:353-69.
43. Fasbender U, Deller J, Wang M, et al. Deciding whether to work after retirement: the role of the psychological experience of aging. $J$ Vocational Behav 2014;84:215-24.

44. Jetten J, Haslam C, Haslam SA, et al. The social cure. Scient Am Mind 2009;20:26-33.

45. Diener ED, Emmons RA, Larsen RJ, et al. The satisfaction with life scale. J Pers Assess 1985;49:71-5.

46. Shin DC, Johnson DM. Avowed happiness as an overall assessment of the quality of life. Soc Indicators Res 1978;5:475-92.

47. Pavot W, Diener E. Review of the satisfaction with life scale. Psychol Assess 1993;5:164-72.

48. Pavot $\mathrm{W}$, Diener $\mathrm{E}$. The satisfaction with life scale and the emerging construct of life satisfaction. J Pos Psychol 2008;3:137-52.

49. Nelson ME, Rejeski WJ, Blair SN, et al. Physical activity and public health in older adults: recommendation from the American College of Sports Medicine and the American Heart Association. Circulation 2007;116:1094-105.

50. Paffenbarger RS, Hyde R, Wing AL, et al. Physical activity, all-cause mortality, and longevity of college alumni. $N$ Engl $J$ Med 1986;314:605-13.

51. Rogers RL, Meyer JS, Mortel KF. After reaching retirement age physical activity sustains cerebral perfusion and cognition. J Am Geriatrics Soc 1990;38:123-8.

52. Sjoersten N, Kivimaeki M, Singh-Manoux A, et al. Change in physical activity and weight in relation to retirement: the French GAZEL Cohort Study. BMJ Open 2012;2:e000522.

53. Yaffe K, Barnes D, Nevitt M, et al. A prospective study of physical activity and cognitive decline in elderly women: women who walk. Arch Int Med 2001;161:1703-8.

54. Jetten J, Haslam SA, lyer A, et al. Turning to others in times of change: social identity and coping with stress. In: Stürmer S, Snyder M, eds. The psychology of prosocial behavior: group processes, intergroup relations, and helping. Oxford, UK: Blackwell, 2009:139-56.

55. Howell JL, Koudenburg N, Loschelder DD, et al. Happy but unhealthy: the relationship between social ties and health in an emerging network. Eur J Soc Psychol 2014;44:612-21.

56. Diener $\mathrm{E}$, Inglehart R, Tay L. Theory and validity of life satisfaction scales. Soc Indicators Res 2013;112:497-527.

57. Diener E, Suh EM, Lucas RE, et al. Subjective well-being: three decades of progress. Psychol Bull 1999;125:276-302.

58. Diener E, Suh E. Measuring quality if life: economic, social, and subjective indicators. Soc Indicators Res 1997:40:189-216.

59. Idler EL, Benyamini Y. Self-rated health and mortality: a review of twenty-seven community studies. J Health Soc Behav 1997:38:21-37.

60. Bailey M, McLaren S. Physical activity alone and with others as predictors of sense of belonging and mental health in retirees. Aging Ment Health 2005;9:82-90.

61. Jetten J, Haslam C, Haslam SA, et al. How groups affect our health and well-being: the path from theory to policy. Soc Issues Policy Rev 2014;8:103-30.

62. Banks J, Muriel A, Smith JP. Attrition and health in ageing studies: evidence from ELSA and HRS. Longit Life Course Stud 2011;2:1-29.

63. Zhan Y, Wang M, Liu S, et al. Bridge employment and retirees' health: a longitudinal investigation. J Occup Health Psychol 2009;14:374-89. 